SAM MLUNG GöSCHEN BAND 79/79a

\title{
GOTISCHES ELEMENTARBUCH
}

\author{
GRAMMATIK, TEXTE MIT UBERSETZUNG \\ UND ERLÄUTERUNGEN
}

von

DR. HEINRICH HEM PEL

o. Professor an der Universität Köln

Dritte, umgearbeitete Auflage

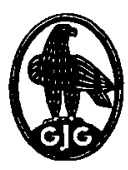

WALTER DE GRUYTER \& CO.

vormals G. J. Göschen'sche Verlagshandlung - J. Guttentag,

Verlagsbuchbandlung · Georg Reimer - Karl J. Trübner • Veit \& Comp.

B E R L I N 1962 
(C)

Copyright 1962 by Walter de Gruyter \& Co., vormals G. J. Göschen'sche Verlagshandlung / J. Guttentag, Verlagsbuchhandlung / Georg Reimer / Karl J. Trübner / Veit \& Comp., Berlin W 30, Genthiner Straße 13

Alle Rechte, einschlieBlich der Rechte der Herstellung von Photokopien und Mikrofilmen, von der Verlagshandlung vorbehalten. - Archiv-Nr. 7330627. Satz und Druck: Walter de Gruyter \& Co., Berlin W 30. Printed in Germany 